\title{
WHY DOES COLLABORATIVE LEARNING NOT ALWAYS WORK EVEN WHEN THE APPROPRIATE TOOLS ARE AVAILABLE?
}

\author{
Dr. Perienen APPAVOO \\ ORCID:0000-0002-4076-0739 \\ Open University of Mauritius \\ Reduit,MAURITIUS \\ Dr. Kaviraj Sharma SUKON \\ OORCID: 0000-0002- 5422-964X \\ Open University of Mauritius \\ Reduit,MAURITIUS \\ Abheenaye Chauhan GOKHOOL \\ OORCID: 0000-0002-4670-0710 \\ Open University of Mauritius \\ Reduit,MAURITIUS \\ Vandanah GOORIA \\ OORCID: 0000-0002-1805-6964 \\ Open University of Mauritius \\ Reduit,MAURITIUS
}

Received: 10/10/2018 Accepted: 21/12/2018

\begin{abstract}
Today, more and more working adults are opting for the Open Distance Learning (ODL) mode to pursue their tertiary studies as it offers them the flexibility to study anywhere, any time and at one's own pace. But studying at a distance can be problematic for many learners, with the absence of regular traditional face-toface sessions. Some find it difficult to adapt to this new learning environment and become easily isolated. Collaborative Learning (CL) can help overcome this isolation and boost learning performance. To investigate the implications of CL in the ODL environment, a study was conducted with 155 learners at the Open University of Mauritius. The study revealed that at least one third of the respondents were not participating in CL and were thus missing on the benefits of "learning together". The others had adopted CL to understand the course content, discuss assignments and get better marks. This study also showed that tutors' role was vital in encouraging learners delve in CL. Respondents deplored the lack of appropriate infrastructure and meeting places to hold CL meetings. They also reported lack of awareness of the benefits of CL and difficulty in finding time due to family and professional commitment as some of the obstacles to CL.
\end{abstract}

Keywords: Collaborative learning, technological tools, group work, open and distance learning, social interaction, Open University. 


\section{INTRODUCTION}

The concept of Collaborative Learning (CL) has much been privileged in the distance mode of learning and thus elicits interest for research. According to Colbeck, Campbell and Bjorklund (2000), Jacobs, Power and Loh (2002), Yazici (2005), Laal \& Laal (2012), CL is an activity in which two or several learners learn, share ideas or attempt to learn collectively to better understand a subject. Sprouting number of research concentrates on learning in group settings and in Computer-Supported Collaborative Learning (CSCL) settings in conventional universities, but few empirical studies have examined Open Distance learners' satisfaction and performance in Collaborating Learning in a blended learning environment. Many scholarly works such as those of Johnston, James, Lye and McDonald (2000), Ellis (2003), Maesin, Mansor, Shafie and Nayan (2009); Jiang (2009), Laal and Ghodsi (2012), and Sansivero (2016) highlight the benefits of collaborative learning, which amongst others include learner motivation, better marks, promotion of social interaction, critical thinking, and combatting isolation which is germane to distance education. In Mauritius, there is no empirical research which has been conducted to investigate these issues in a collaborative blended learning environment. This paper considers a case study of the Open University of Mauritius, a young but fast growing University offering thousands of learners, principally working adults, the opportunity to embark into tertiary education or pursue further studies for professional advancement. The study should unveil salient information about what motivates or hinders learners from engaging in Collaborative Learning. The findings of this study will fuel the debate around the concept of Collaborative learning at the University and provide the necessary guidelines for a conducive collaborative learning environment. This should help the university combat dropout which is common across all universities, but particularly distinctive for learners who are enrolled in a blended program.

\section{LITERATURE REVIEW}

\section{Collaborative Learning Theory: ODL Perspective}

The term collaborative describes a situation where leaners of more or less the same academic performance can do similar activities and work towards a common goal (Muuro, Wagacga, Oboko, \& Kihoro, 2014). Two theories namely, motivational theory and socio-constructivism, provide a comprehensive theoretical framework that might explain why learners adopt the collaborative learning in an ODL environment. Collaborative learning is a cordial interaction that involves both learners and teachers in the acquisition and sharing of experience and knowledge (Zhu, 2012). Learners show greater interest and participate more actively in a constructivist learning context which promotes critical reasoning and in-depth inquiry (Mayes, 2001). In collaborative written assignments, group discussions and debates, learners can strengthen knowledge construction. Social learning theories aid us to learn from each other and also teach us how to construct active learning community (Brame, 2016).

In the pedagogy of teaching, learners are given the liberty to learn from one another as pointed out by Vygotsky (1978). He explored the causal relationships between social interaction and individual learning providing a grounded context of social constructivist theory of learning. He mentioned that learning unfailingly happens and cannot be separated from a social context. "From a teaching philosophy perspective, CL is compatible with constructivism basically owing to the function of social interaction. Eggen and Kauchak (2001) reported that in a CL environment, learners co-construct more powerful understandings than if they were to construct alone. In addition, other researchers highlighted how the learning theories of connectivism and constructivism might conformingly be used in education technology for the new generation (Mattar, 2010). Consequently, pedagogical strategies that nurture the sharing of expert knowledge where learners collaboratively conduct research, share their results, and produce a final project, help to create a collaborative community of learners. Collaborative learning in fact involves joint construction of meaning through interaction with other learners (Law \& Wong, 2003). Van Merrienboer and Paas (2003) added that accomplishing a task while working together breeds a powerful conducive learning environment to facilitate the active construction of knowledge. Because previous studies have mostly examined learner's performance and satisfaction in a conventional set up (Stansfield, McLellan, \& Connolly, 2004) there is a need to investigate what ODL learners opine of such a learning paradigm. 


\section{Tools/Techniques in Collaborative Learning}

Emerging technologies are altering the ways learners communicate, collaborate and learn through social interaction. According to Laal and Laal (2012), learners form small groups to help each other to complete some tasks such as their assignments. Learners conduct the face to face meetings either before or after the sessions. In some cases, learners conduct the meetings during the sessions with the approval of their respective tutors. In collaborative learning, learners are able to acquire knowledge through discussions and exchange of opinions among themselves (Brindley, Walti, \& Blaschke, 2009).

Common tools which are currently used during collaborative learning are WhatsApp, Skype and Moodle. The latter is commonly used in most universities and Cole (2005) observed that Moodle can be defined as a facilitator in collaborative learning, whereby tutors can create several activities for learners to discuss or even share their ideas. Tutors act as moderators while learners discuss among themselves. Learners can use the chat function to create a group and discuss their assignments. Rabbany, Elatia, Takafolli and Zaiane (2013) confirmed that Moodle indeed enables learners to participate in collaborative learning.

Another very popular tool used by learners is Skype which according to Zygouris-Coe (2012) is used to conduct group discussion. The author found that learners create their own group on Skype and set up their own ways of conducting collaborative learning. Some learners form a learning group on Skype to complete a task which was allocated to them (Lan, Sung, \& Chang, 2007). Authors like Hrastinski and Aghaee (2012) explained the advantage of using Skype in collaborative learning, like getting instant feedback from other learners on a subject of discussion or still catching up with another learner for a missed tutorial or discussion session.

Because of its popularity learners have found WhatsApp convenient to be integrated in collaborative learning. Amry (2014) identified several ways in which learners use WhatsApp allowing them to create specific groups in which they exchange messages, pictures, documents and videos. Chan (2005) added that WhatsApp provides opportunities for learners to cooperate and collaborate together to share ideas and knowledge. Preston, Phillips, Gosper, McNeill, Woo and Green (2010) also found out that more than 50\% of learners prefer to learn on groups such as WhatsApp group where they are able to discuss freely their academic problems.

A famous technique of collaborative learning is the use of group work to learn a task. Learning is more effective when peers come together to share ideas about a problem (Johnson \& Johnson, 1989). Lin (2015) posits that group work is a precondition for effective CL. Learners develop effective cognitive learning strategies through group discussion and social interactions. Group discussion is one of the key activities of collaborative learning (Zhu, 2012). Garrison and Cleveland-Innes (2005) confirmed that the activity of group discussion is indeed effective in helping learners perform better. CL can thus help learners to gain more knowledge while working on their assignments if they work together rather than working alone.

But group work has its own challenges. One group member may not master learning as quickly as the others and can be left behind and ultimately not be able to learn anything from the group work. Consequently, the whole group might end up falling apart. Svolik (2009) also drew attention to the balance of power as one of the biggest problems of a group situation, where dictatorship is recurrent. Moreover conflicting personalities might interpose with each member's chance to fully participate in collaborative group learning.

\section{Perceived Satisfaction from ODL Learners on CL Practices}

Dewiyanti, Brand-Gruwel, Jochems and Broers (2007) describe learners' satisfaction with collaborative learning "as the degree to which a learner feels a positive association with his/her own collaborative learning experiences." Nurmela, Palpen, Lehtinen and Hakkarainen (2003) said that effective learning occurs if learners are actively involved, rather than being passive listeners. Previous studies highlighted that learners who delved in online collaborative tasks were more satisfied with their learning compared to those who abstained from CL (Jung, Choi, Lim, \& Leem, 2002). Learners in CL conditions demonstrate more constructive learning processes (Eichler, 2003). 


\section{Role of Tutors in Collaborative Learning (CL)}

Although the concept of collaborative learning is about learners learning by themselves, tutors do have several roles to play in these situations. Laal and Laal (2012) stated that a tutor can facilitate the learning process of learners and help them to tackle their issues by frequently asking them questions. While some learners can work independently on their CL sessions, others depend on a facilitator to conduct their group sessions for such tasks as planning and preparing the group sessions, listening to the discussions being held and providing feedback and encouragement. Additionally, the tutor is also present to deal with any divergence taking place and to monitor the discussion.

This is in no way contradictory to the idea of learner autonomy that requires learners to be independent and become lifelong learners. Lin (2015) views CL as a means of moving learners "away from their dependence on their teachers and learn on their own". But, as pointed out by Katz and O'Donnell (1999), the role of the tutor in CL is to intervene during negative situations and to correct the problems which arise. Lentell (2003) explained that a tutor should facilitate and guide learners so that they can understand the subject they are studying and also gain more knowledge through collaborative learning.

Benefits and challenges of Collaborative Learning

Research has shown that there is a lot of benefits related to collaborative learning. The potential level of progress is increased when a learner works collaboratively with more capable peers. Lin (2015) stated that a learner's cognition is increased by actively communicating with more efficient peers and thus expanding conceptual potential. During the CL process, learners have the chance to both receive input and as well as produce output.

Learning does not only necessitate cognitive skills but also involves aspects of how learners feel about learning (Jiang, 2009). Motivation is considered as an important factor that determines learner's achievement and attainment through collective aims (Dornyei, 2001; Schreiber \& Valle, 2013). Brindley et al. (2009) proposed different methods to inspire learners to confront the value of CL by creating study group experiences that are motivating and fruitful. The rationale of the CL structure implies that if learners understand group success, they will be motivated to help one another to achieve a better result (Zhang, 2010).

$\mathrm{CL}$ also breeds a positive learning climate environment where learners feel much closer and more at ease without being watched by the whole class or the teacher. Delucchi (2006) highlighted that they have the possibility to express their own opinions, the environment being more conducive, thus enabling effective learning. There is firm empirical ground that learners who are more satisfied with the online learning experience are less likely to drop out and derive higher motivation to continue, but, it is harder if the educational technology is not exploited by learner in a fully online environment (Joo, Lim, \& Kim, 2011; Lee \& Choi, 2013).

CL participation boosts learners in critical thinking through problem-solving process, enhancing them more in drill-practice skills (Maesin et al., 2009). CL contributes to learners' performance and improves their learning process as well (Rovio-Johansson and Lumsden, 2012). In addition, CL can also help learners to prepare for their exams with more confidence as stated by Picou (2011). CL is proved to be more effective for problem-solving experiments or worked examples than individual learning. Retnowati, Ayres and Sweller (2017) further supported that collaboration is more beneficial and effective when learners learn under problem solving conditions.

Web-based technology no longer posits a challenge in an online learning environment as long as the accessibility, usability and support of the course technology platform are available to facilitate learners (Sun, 2016). In the context of ODL, a technology tool is considered as effective for learning if a learner is using and associating a positive attitude in a way that is helpful in reaching his/her learning goal. Therefore, a tool allowing collaborative learning, may achieve the learning goal as highlighted by Weidlich and Bastiaens (2018). There is further support from De Jong, Krumeich and Verstegen (2016) that the blended model-based CL in a Small Private Online Course (SPOC) environment with proper design, facilitation and face-to-face interaction groups provided opportunities to learners to engage in learning in order to improve their achievements. On the other hand, researchers (Curtis \& Lawson, 2001; Brindley et al., 2009; Weidlich \& Bastiaens, 2018) have also highlighted several hindrances to CL and which include time and 
work constraints, family and personal commitments, lack of learners' readiness to work in groups and time differences for members of the group from different regions. Many issues emerged from ODL learner's point of view: finding it difficult to communicate with people whom they do not know well, difficulty of time delays in the communication process (asynchronous rather than real-time), members in the collaborative group do not maintain an agreed or expected work schedule, need to rely on others to complete the entire tasks and finally collaboration as a learning activity itself is time consuming. Learners do not always find it easy to take part actively in CL sessions; shy learners can feel overwhelmed when the focus is totally put on them and it takes time, patience and skills to hold them as confident contributors especially in group activities (Pearson, 2010).

Moreover there is also the issue of the interface design to ease collaboration in an online environment. Additional instructional material on the effective use of the software dedicated for collaborative learning is at times costly for most institutions in higher education. Another important factor propounded by Sanders (2008) and Brindley et al. (2009) is that learners are at times "ill-equipped through their previous learning experiences to collaborate or peer-review and often see friends as rivals."

\section{Research Questions}

To meet the objectives of this study the following research questions will be addressed:

- What are the current Collaborative Learning practices of learners at the Open University of Mauritius?

- What are the factors promoting or hindering CL practices?

- Which measures can be implemented to enhance CL practices?

\section{RESEARCH METHODOLOGY}

A mixed-method approach was adopted whereby both quantitative and qualitative data were collected to provide a holistic understanding of the research problem. An online questionnaire was designed to collect data from learners who were either still pursuing or who had just completed their studies at the Open University of Mauritius. The questionnaire comprised 84 items divided into 6 sections. The set of items present in the questionnaire was guided and developed based on the conceptual elements in the literature review. Before finalizing the questionnaire, a pilot testing was undertaken during one week among 10 randomly identified learners of the institution and changes were brought based on their feedback. The survey was administered over a period of 3 weeks and responses were analysed using SPSS.

\section{DATA ANALYSIS AND FINDINGS}

\section{Descriptive Analysis}

One hundred and fifty-eight ODL learners responded positively to the call to fill out the online questionnaires. After data screening, 155 questionnaires were retained. There was a higher percentage of female respondents (66.9\%). The respondents' age varied mostly between 18 to 50 . Half of them were married. Most of them rated their IT skills as good or very good, using tools like laptops, mobile phones, PCs and tablets on a regular basis. The first item of the questionnaire filtered out $37 \%$ of the respondents who did not participate in collaborative learning $(\mathrm{CL})$. This implies that slightly more than one third of the respondents were not availing themselves of an important tool, that of collaborative learning, which as per numerous authors (Ellis, 2003; Jung et al., 2002; Laal and Laal, 2012) a vital component of online and, open and distance learning. Further data analysis was thus based on the 97 respondents who participated in CL during their studies. 


\section{Preferred Tools for CL Activities}

Most of the collaborative groups consisted of 3-7 people, hence showing that they preferred small-size groups, probably to be more organized and effective. Two thirds of them were having meetings at least once a week and the most common tools utilized during CL sessions were face to face meetings, emails, WhatsApp, mobile phones and the Moodle platform. Figure 1 shows on a scale of 1-4 (never use- most preferred), the responses for use of such tools.

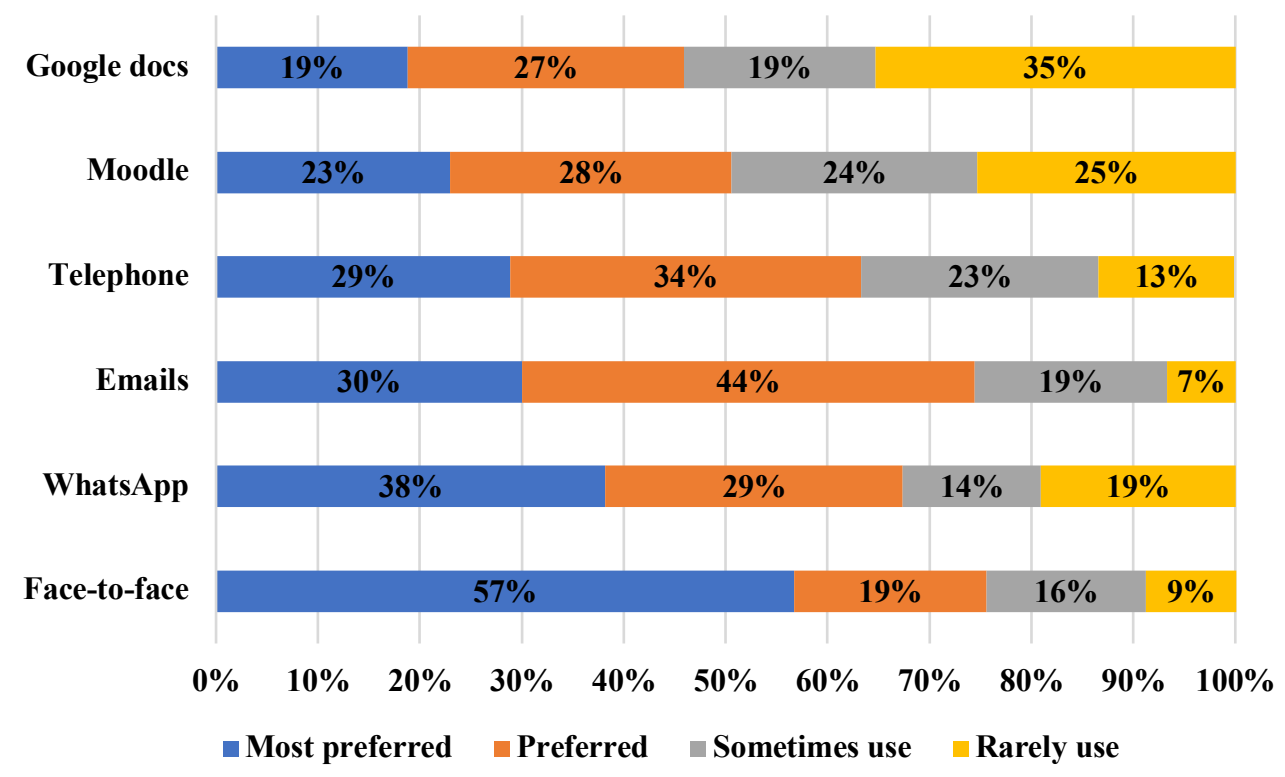

Figure 1. Preferred tools during CL.

Moodle is the primary online learning platform at the Open University of Mauritius. This study revealed that nearly half of the learners were not making regular use of this platform in their studies. This calls for urgent attention as learners were missing the benefits of this tool, where learning materials, videos of tutorial sessions and lectures, assignments and submission deadlines are posted and important information communicated. The platform Moodle in the ODL environment has been widely appraised for its benefits (Cole, 2005) and not availing themselves of such benefits therefore deprived learners of the University of a prime avenue to enhance their learning.

Regarding the timing, most of those who opted for CL chose to do so right after tutorial sessions normally held on Saturdays as this proved to be more convenient and practical, helping to save on travelling time. 


\section{Preferred Place for CL Meetings}

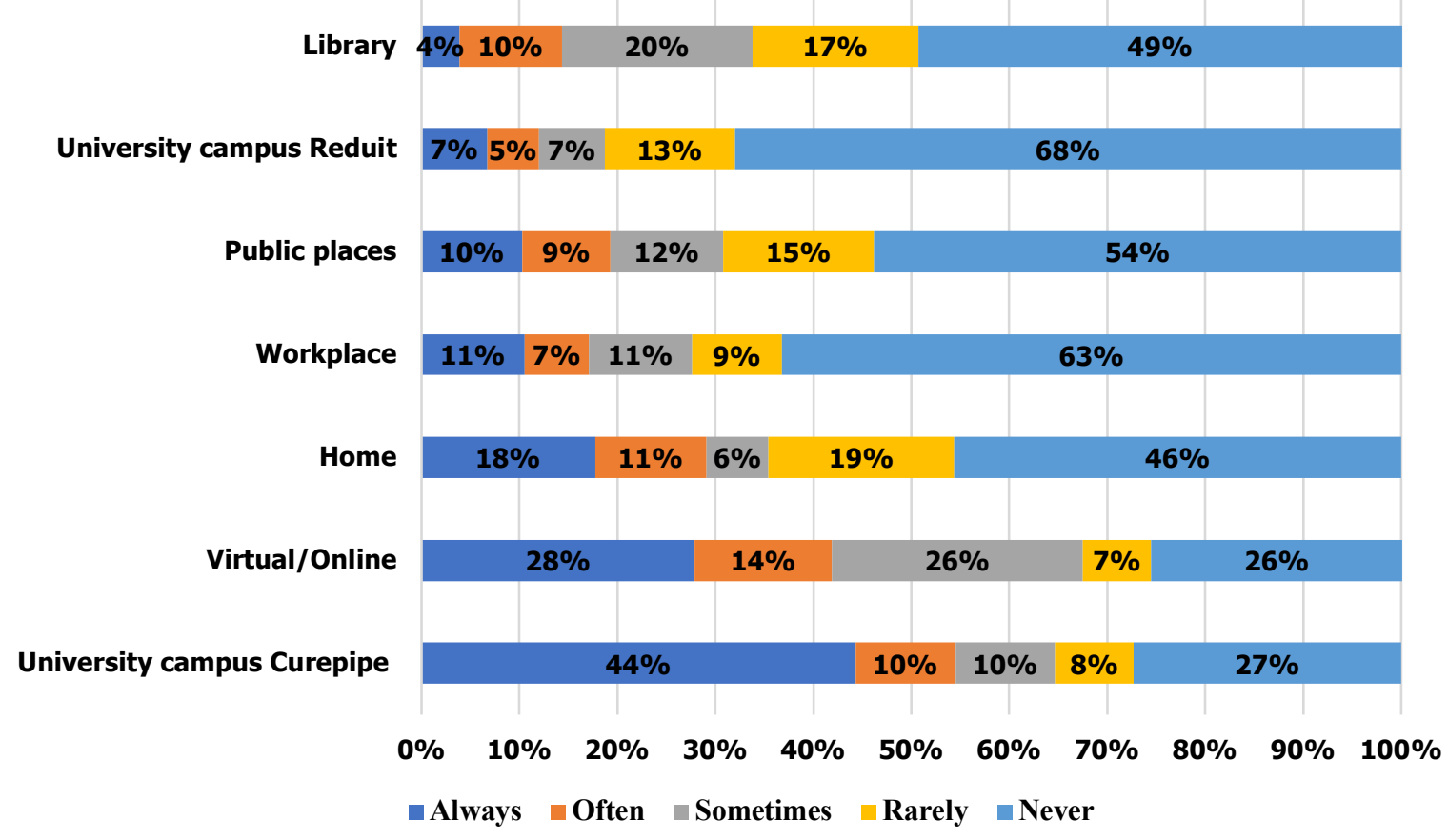

Figure 2. Preferred place for CL meetings.

Figure 2 depicts the most preferred place for collaborative learning. The University campus at Curepipe, where most of the tutorial sessions are held, was the most favorite place of learners to hold the CL sessions. This is in line with the data obtained from learners where they affirm that they schedule their CL sessions mainly after tutorial sessions on Saturdays. The second preferred mode for facilitating collaboration was the virtual/online platforms such as emails, WhatsApp and Moodle as outlined in figure 2. This preference for online meeting platforms reflects today's trend towards e-learning, where both synchronous and asynchronous interaction makes learning a more dynamic, interactive and engaging process (Amry, 2014; Kuo, Belland, \& Kuo, 2017).

One item of the questionnaire collected tutors' role in encouraging learners to delve in CL. While data revealed that most tutors did encourage learners to get involved in CL, less than half of them did that on a regular basis.

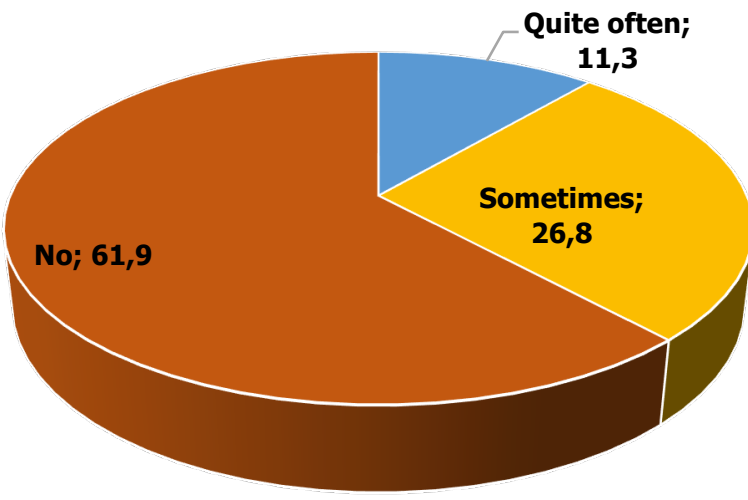

-Quite often $\quad$ Sometimes $\quad$ No

Figure 3. Tutor involvement.

The role of tutors can be crucial if learners are to benefit from CL activities (Lentell, 2003; Lin, 2015). 


\section{Role of Tutors in CL}

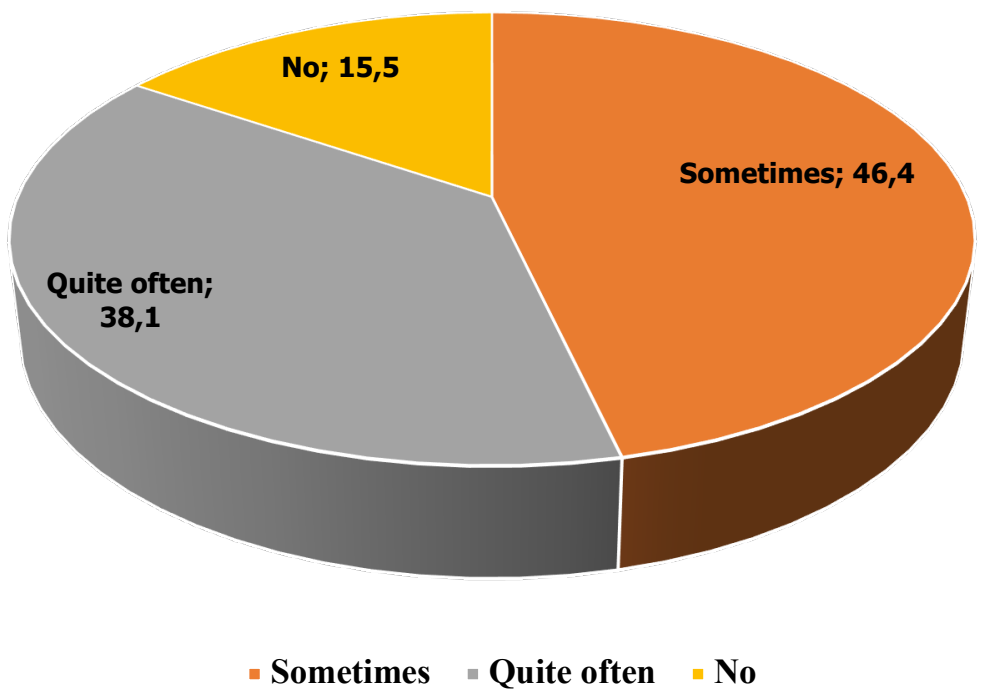

Figure 4. Tutor encouragement.

Tutors can play a vital role in the adoption of collaborative learning. They do not only act as mediators who support learners maximize their ability to assimilate difficult concepts, but they are also responsible for structuring group interaction and assigning cognitive roles to them (Lin, 2015). Sixty-two percent of learners stated that their tutors did not get involve at all in collaborative learning, while $26.8 \%$ admitted that they sometimes participated. Learners reported that the tasks of those tutors who were involved in CL were principally to encourage learners to interact with each other $(62.3 \%)$ and guide the discussions $(60.7 \%)$. This shows the need for tutors to be empowered to communicate the benefits of CL to learners, motivate them to get involved in such activities and be involved in the process.

\section{Factors Contributing to CL}

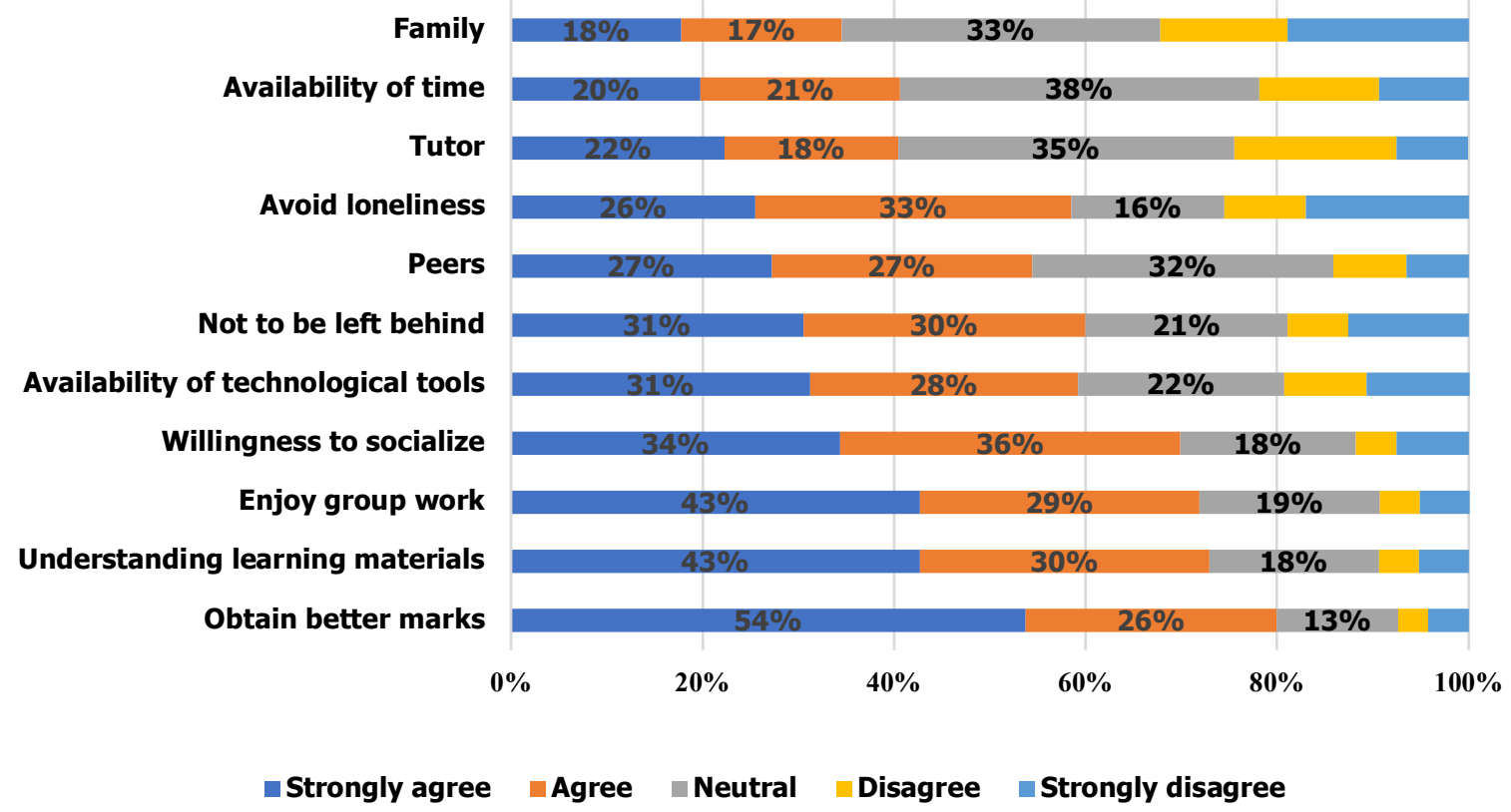

Figure 5. Factors contributing to CL. 
Various factors contributed to learners' involvement in CL. The main ones were to understand the learning materials and obtain better marks. From a social point of view, learners also got involved in CL to avoid loneliness and interact with peers. They also confirmed that the availability of technological tools was an important factor contributing to their participation in CL as revealed in studies by Zhu (2012) and Amry (2014). Moreover, only $40 \%$ of respondents felt that tutors contributed to their CL, hence confirming the previous findings.

\section{Benefits of CL}

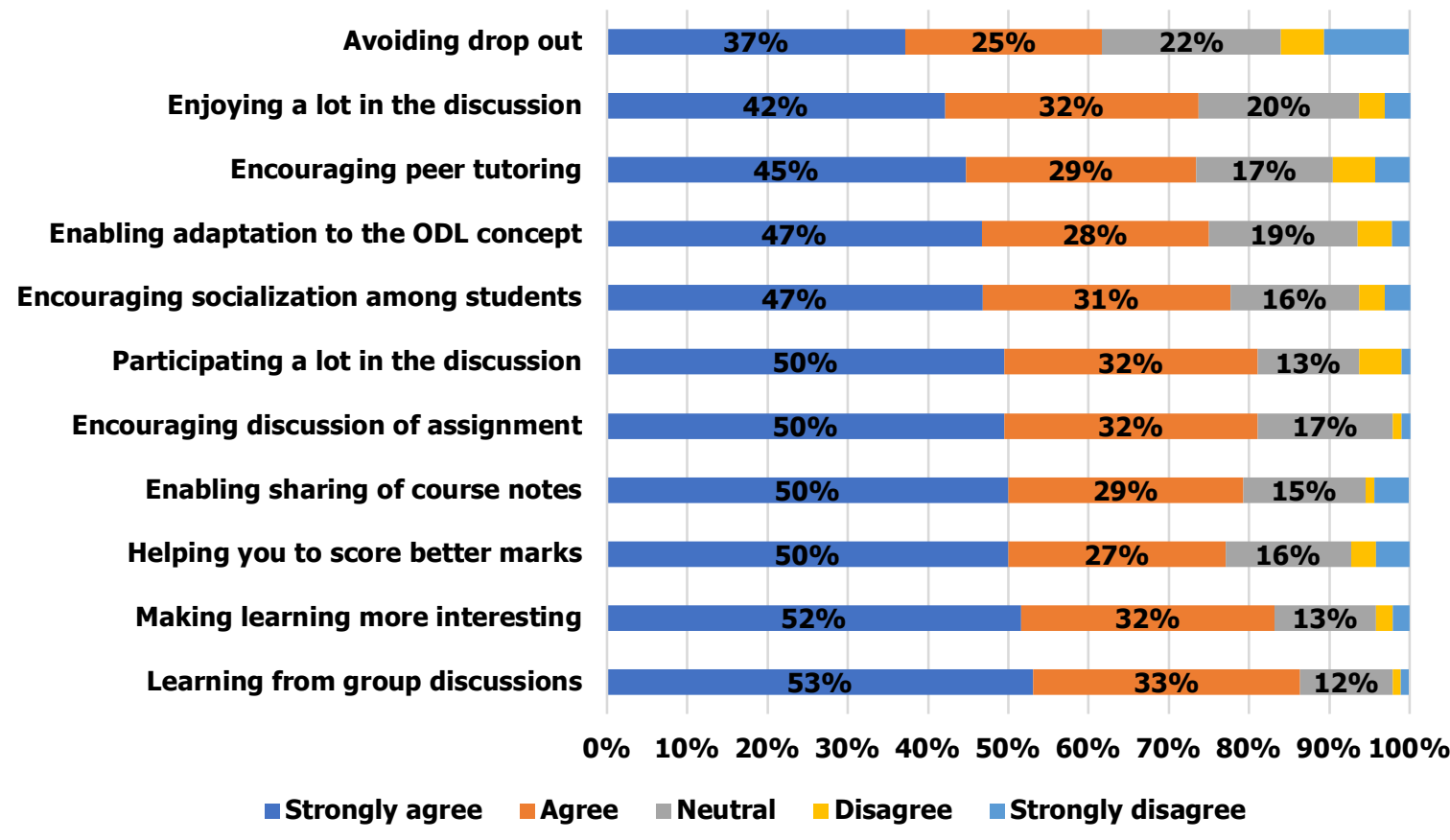

Figure 6. Benefits of CL.

Most of the respondents gave high ratings to the different benefits they derived from collaborative learning. $\mathrm{CL}$ encouraged learning through group discussions, making the whole process more interesting. Learners were of the opinion that CL enabled them to share course materials and improve exam scores. Because the ODL mode is a relatively new concept, learners valued CL as an enabler in the adaptation process, promoting at the same time socialization and peer tutoring. Quite a number of respondents (62\%) believed that involvement in CL can help avoid drop out. Research shows that in the ODL environment, dropout rates are higher than those for on-campus courses and range from 20 to $50 \%$ for distance learners (Frankola, 2001). So, the promotion of CL can help ODL institutions curb down their drop rates (Pedro \& Scott, 2004). 


\section{Description of Learning Style}
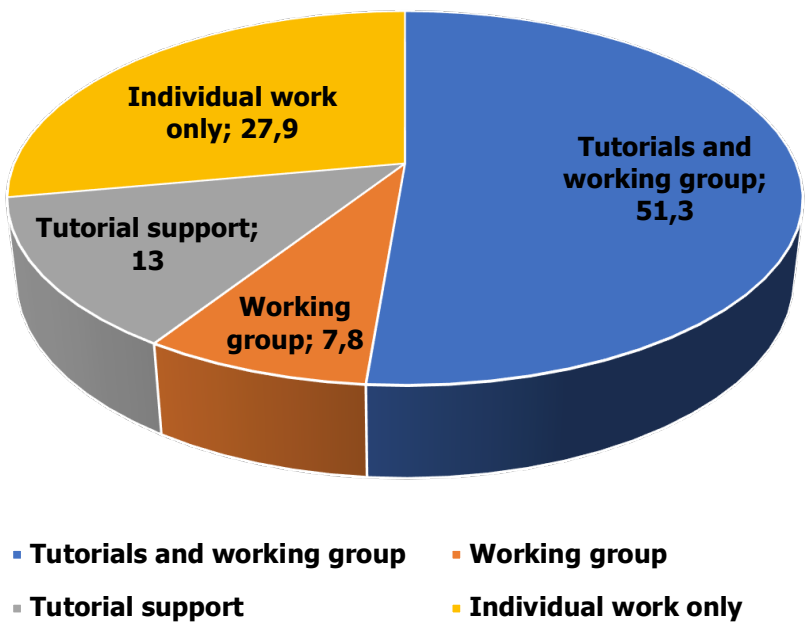

Figure 7. Description of learning style.

One item of the questionnaire investigated the respondents' learning style and helped to triangulate data about those participating in CL or not. Figure 7 shows that around 60\% of respondents were involved in working groups and this indicates good triangulation and confirmed responses to a previous item which revealed that slightly less than two thirds of respondents were involved in CL. Thirty-six percent did not attend any tutorials which offer learners the opportunities to meet each other, and hence plan and organize CL activities. Data show that those who attended the tutorials were more likely to participate in CL. Universities might suggest compulsory attendance of a certain percentage of tutorials to foster learners' involvement in CL.

\section{Planning of CL Activities}

For CL to be fruitful, it must be properly organized and planned so that meeting time is maximized. Three sections of the questionnaire investigated issues dealing with the planning of CL and the activities taking place during and after (De Jong et al., 2016). Figure 8 shows that more than half of the respondents considered the planning stage of CL as inadequate. Meeting place was not always convenient. The duration of the meeting and the contribution of each participant were not defined. Pre-planning tasks were not set before the meetings were held. In most cases $(72 \%)$ there was no group leader to coordinate the activities. This lack of planning can be a deterrent to the conduct of CL and even jeopardize its outcomes.

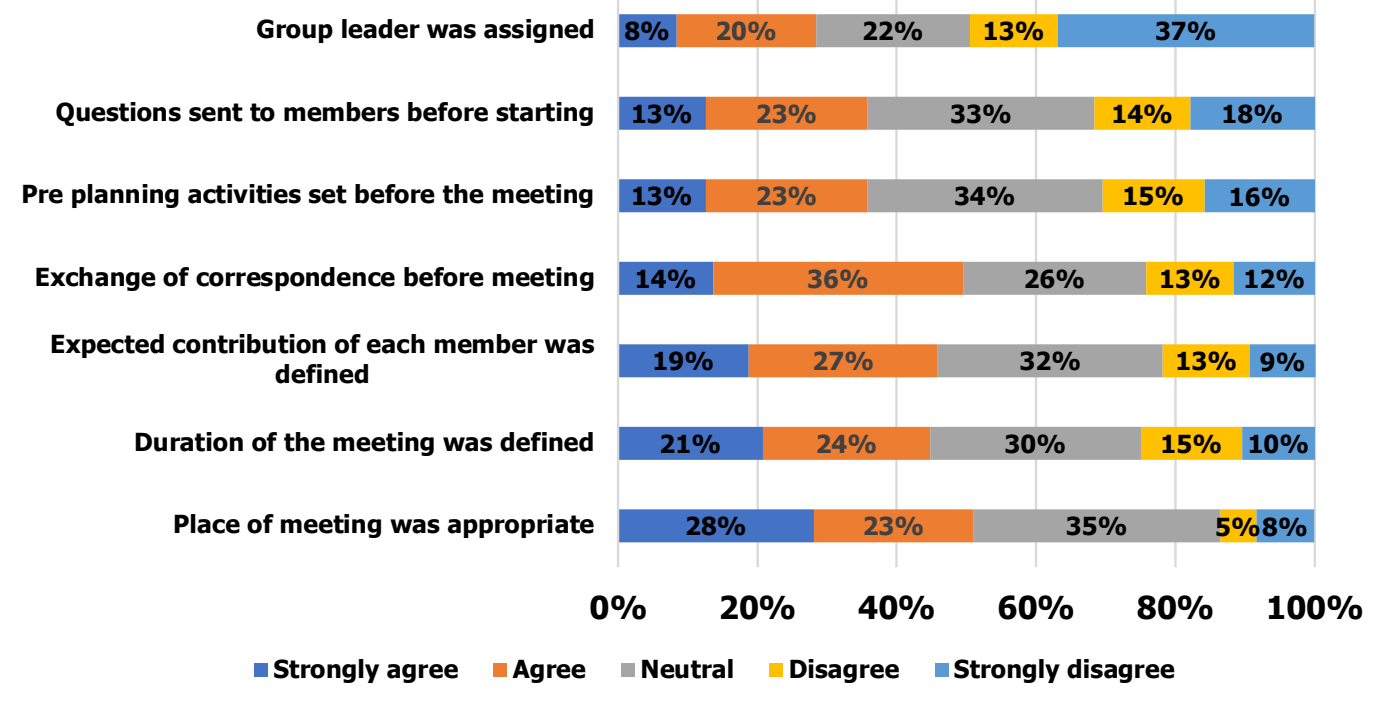

Figure 8. Planning of CL. 
Respondents reported that during the meetings, a number of fruitful activities like sharing of notes and discussion of assignments took place. CL was also a popular learning platform for more than half of them to study the learning materials together and conduct revision before exams. But figure 9 also shows that a significant percent of learners was either not convinced of the worth of the CL meetings (neutral or disagree) or did not see much happening in these meetings. This speaks of the efficiency of CL which though attended by a number of learners did not seem to bring the expected outcomes. Learners should probably be provided with more guidelines as to how to organize and plan their CL sessions.

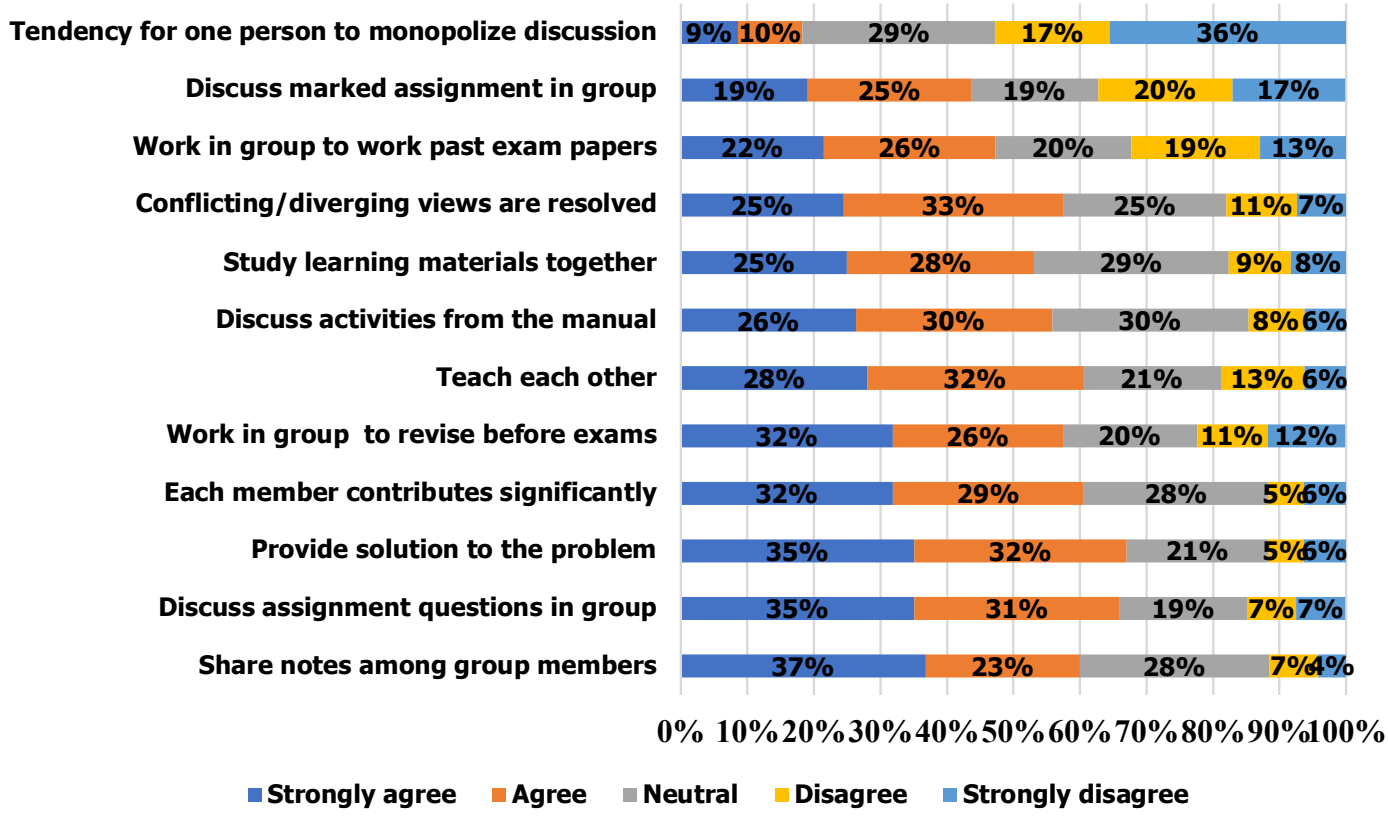

Figure 9. During CL.

One section of the questionnaire collected information about what happened after the CL sessions, to assess if the purpose of these sessions has been met and if future sessions were anticipated. While data revealed overall positive responses (figure 10), attention is drawn to the significant percentages of disagreement for all the items of this section. For example, some $30 \%$ were not willing to meet again were not sure if objectives were met or still if they had understood the materials better. Data therefore showed that the proper planning of $\mathrm{CL}$ is an important factor contributing to effective interaction and learning.

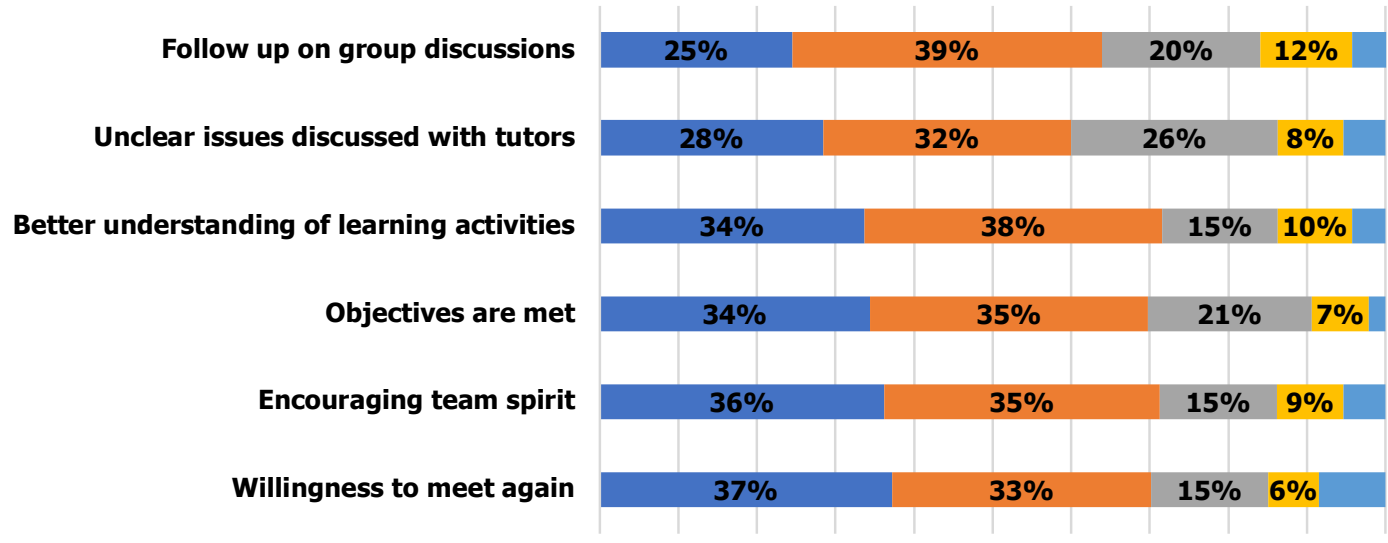

0\% $10 \%$ 20\% 30\% 40\% 50\% 60\% 70\% 80\% 90\%100\%

๙ Strongly agree Agree Neutral Disagree $\backsim$ Strongly disagree

Figure 10. After collaborative learning. 
This study showed that opinions about the outcomes of these sessions were mitigated. While the majority found them quite useful to boost their understanding of the learning content and obtain better exam results, there was still a minority who found the sessions unproductive and some even mentioned their unwillingness to attend future sessions.

\section{Challenges to Participating in $\mathrm{CL}$}

While CL presents numerous benefits, its adoption and implementation can pose a number of challenges which have been reported by (Nyerere, Gravenir, \& Mse, 2012; Curtis \& Lawson, 2001). One section of the questionnaire captured learners' responses in that regard. Around $40 \%$ of the respondents reported work and family commitments and the logistics around the conduct of CL, like, transport problem and lack of appropriate meeting places as the most common challenges to participating in CL. Such issues were also reported by researchers like Pedro \& Scott (2004) and Lin (2015).

Respondents considered that off-topic discussions could also jeopardize the success of CL, especially when there is restricted involvement of the tutor and other peer learners. While educational institutions have no control over the external factors like family and professional commitments, they can review policies and put in place such facilities that can address a number of the challenges mentioned in this study and which corroborate with the findings of Dirkx and Smith (2008).

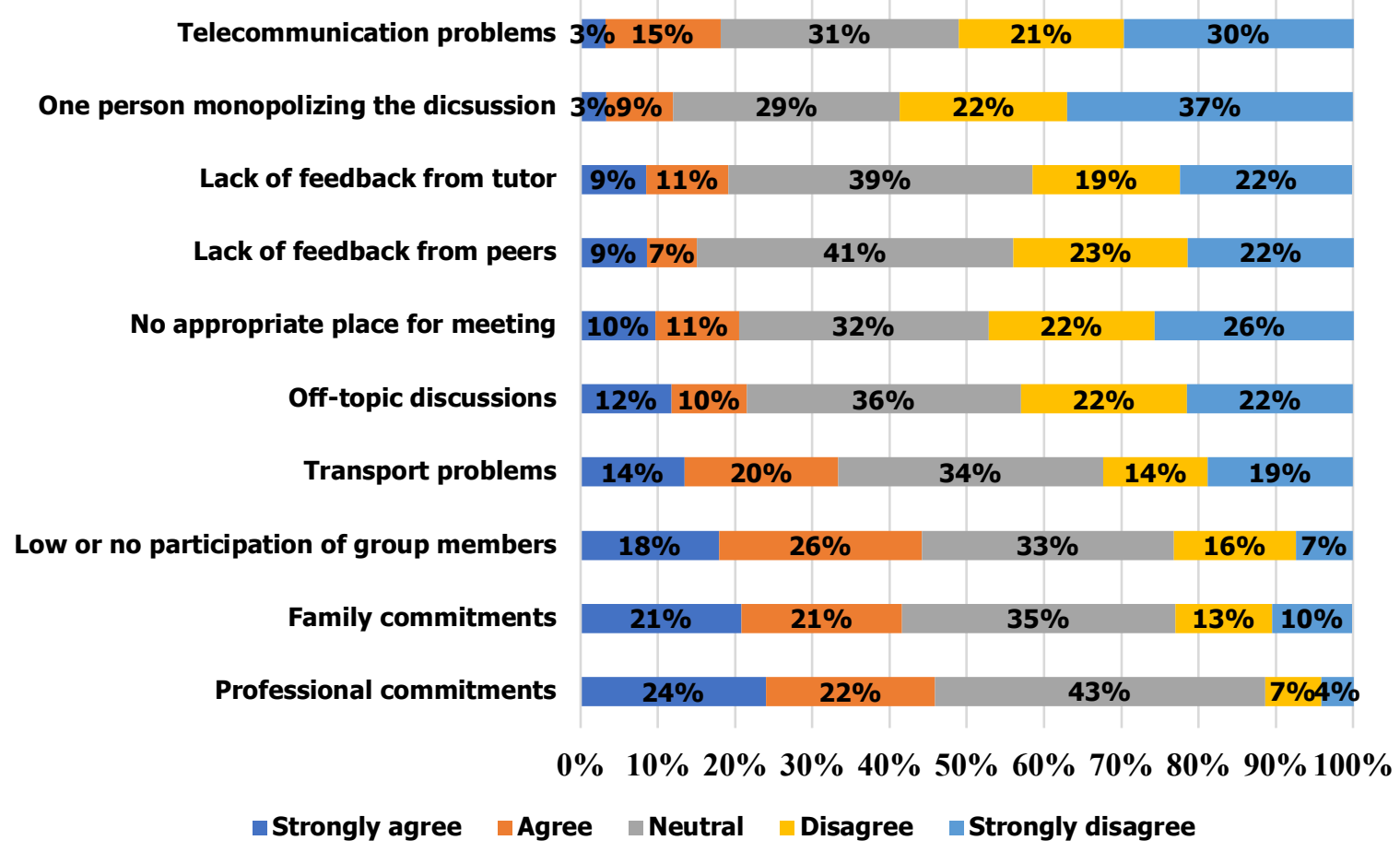

Figure 11. Challenges of CL.

\section{Differentiation by Gender, Age and Marital Status}

When further analysis was carried out to investigate any bias in terms of gender, age group and marital status, no significant differences were observed for most of the cases under consideration. For example, there was no gender bias with regard to responses about obstacles to participation in CL and to styles of leaning. The only significant difference worth reporting $(U=740, p=0.031)$ is that more matured learners, that is those in the age group 31-50 mentioned they enjoyed group work more than the younger ones and that was probably a motivating factor for them to take part in CL. 


\section{Qualitative Analysis}

Three open-ended questions allowed the collection of qualitative data from the respondents. Despite the numerous benefits that CL adds to the learning process, especially in the ODL setup, 37\% of learners at OU indicated that they did not participate in CL. One open-ended question was used to capture the several reasons behind this reluctance. Learners mentioned that time was a crucial factor for not participating in CL (Dirkx \& Smith, 2008) (figure 12).

Most importantly, course design in the ODL context should enable enough time for more collaborative learning activities in terms of scheduling, planning and organizing and subsequently more time is needed for discussion and changing ideas which are crucial to deeper learning (Brindley et al., 2009).

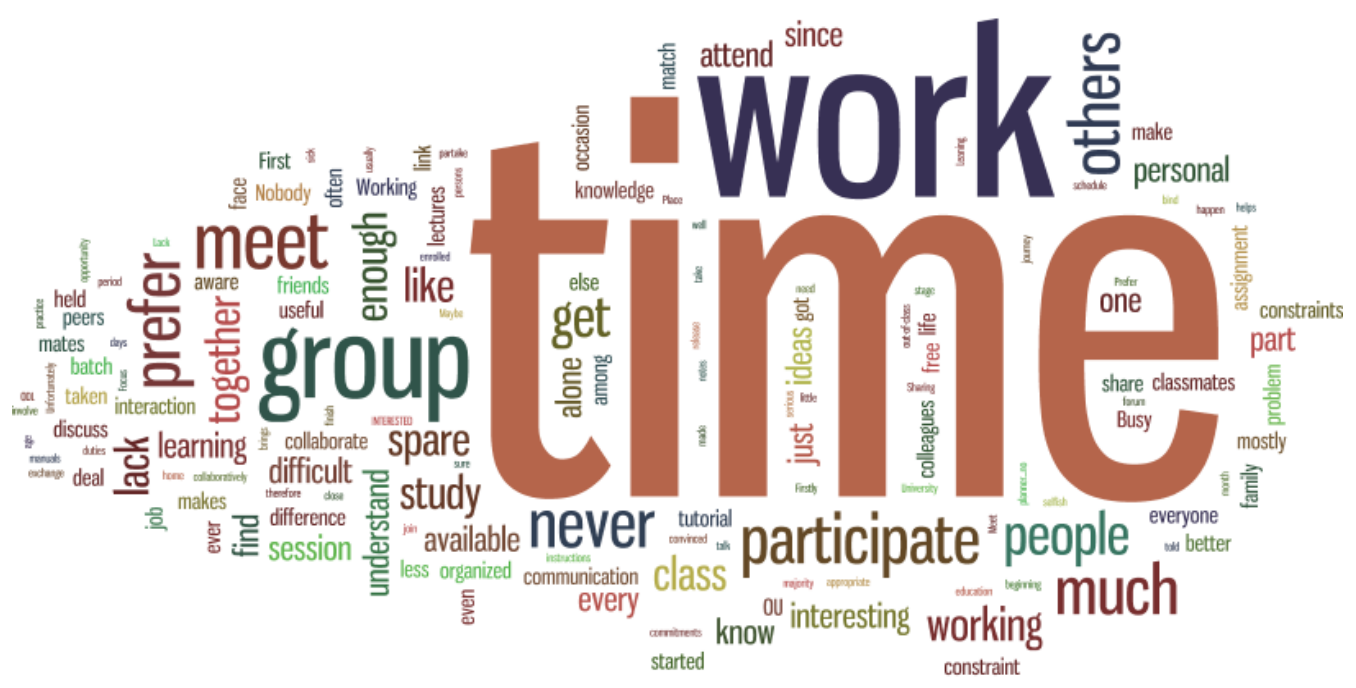

Figure 12. Factors affecting participation in CL

The following comments testify of the views of learners on that issue:

"Working and learning make it difficult to find time for collaborative learning"

"I don't have much time to interact with others"

"I would like to participate in CL, but the majority are working people and barely have time for this"

This trend probably results from the profile of the learners who were mostly working adults with tight personal and professional commitment. What emerged as another major factor from the responses is the tendency to favour individual work, and the difficulty in finding or joining an appropriate working group.

" $\mathrm{PhD}$ is more of a personal journey"

"Learners still believe that if they study alone, they will get more marks. They are not willing to collaborate and work together. They keep their knowledge and notes for themselves, even if someone asks for a help."

Moreover, meeting opportunities were also scarce. Lack of awareness of the benefits of CL was also pointed out as an obstacle to participation in CL. Learners remarked that tutors were not motivating them enough to delve in CL activities.

"I was never aware of it"

"Some tutors do not involve learners in group work"

The emerging themes from the commentaries confirmed the findings revealed from analysis of items from previous sections of the questionnaire: What needs to be retained is that some ODL learners found it difficult to integrate $\mathrm{CL}$ in their learning and lack of time and involvement of tutors and other peers were the major obstacles identified. 
To boost up enthusiasm and motivation to participate in CL activities, learners suggested that the institution provides appropriate meeting places to hold group meetings (figure 13). As already suggested by Nyerere et al. (2012), convenient meeting locations are an important factor to organize CL activities. Other suggestions include access to an enhanced interactive online platform, improved Wi-Fi facilities and access to the library premises. In relation to the previous open-ended question, learners suggested that tutors should not only encourage them to get involved in CL but should also act as facilitators in the process. Some of them also raised the importance of being informed right at the beginning of the semester about such activities and their benefits. The responses below testify of some of these suggestions.

"Provide a special corner for learners willing to participate in collaborative learning"

"Tutors should discuss about collaborative learning and encourage learners to participate"

"Conduct an awareness campaign based on facts (coming from studies/research) whereby the benefits of collaborative learning are passed on to learners and tutors"

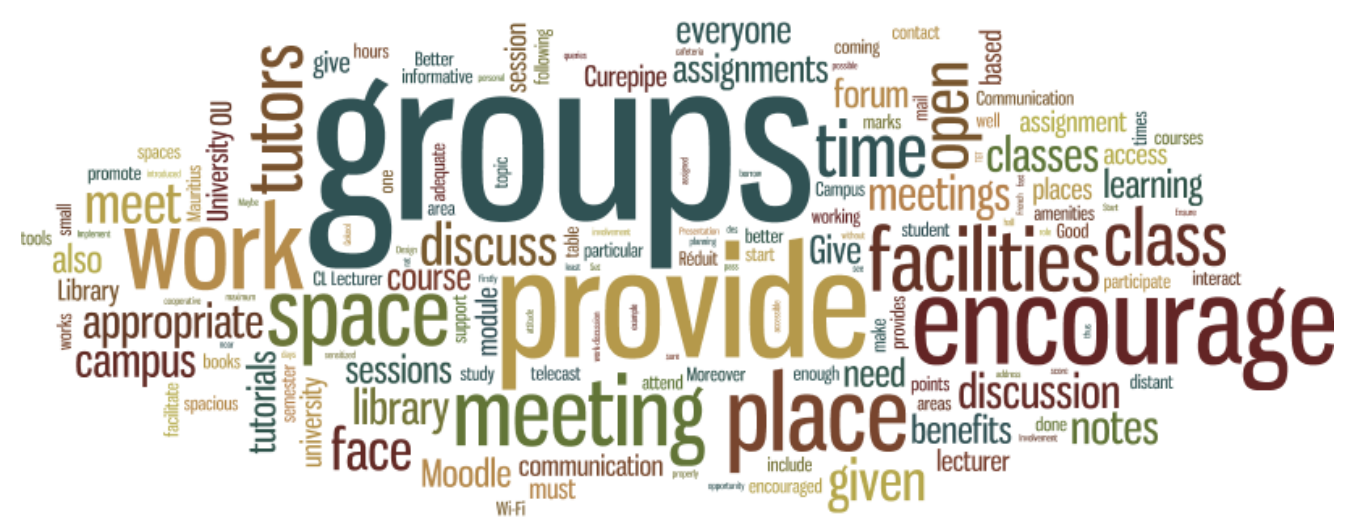

Figure 13. Word cloud describing measures to facilitate CL.

Responses to a third open-ended question lead to some valuable reasons that can encourage ODL learners get involved in CL. These include the benefits of knowledge sharing and helping each other in understanding and assimilating course content (figure 14). The other benefits mentioned by respondents are socialization, group discussions and obtaining better results in both assignments and exams. Respondents also indicated that successful collaborative learning can be facilitated by the presence of tutors who can guide the discussions and help address emerging issues.

"Sharing is caring. By sharing you gain more"

"It encourages learners to get fully involved in the content of the particular module and prepare them to answer exam questions more easily" 


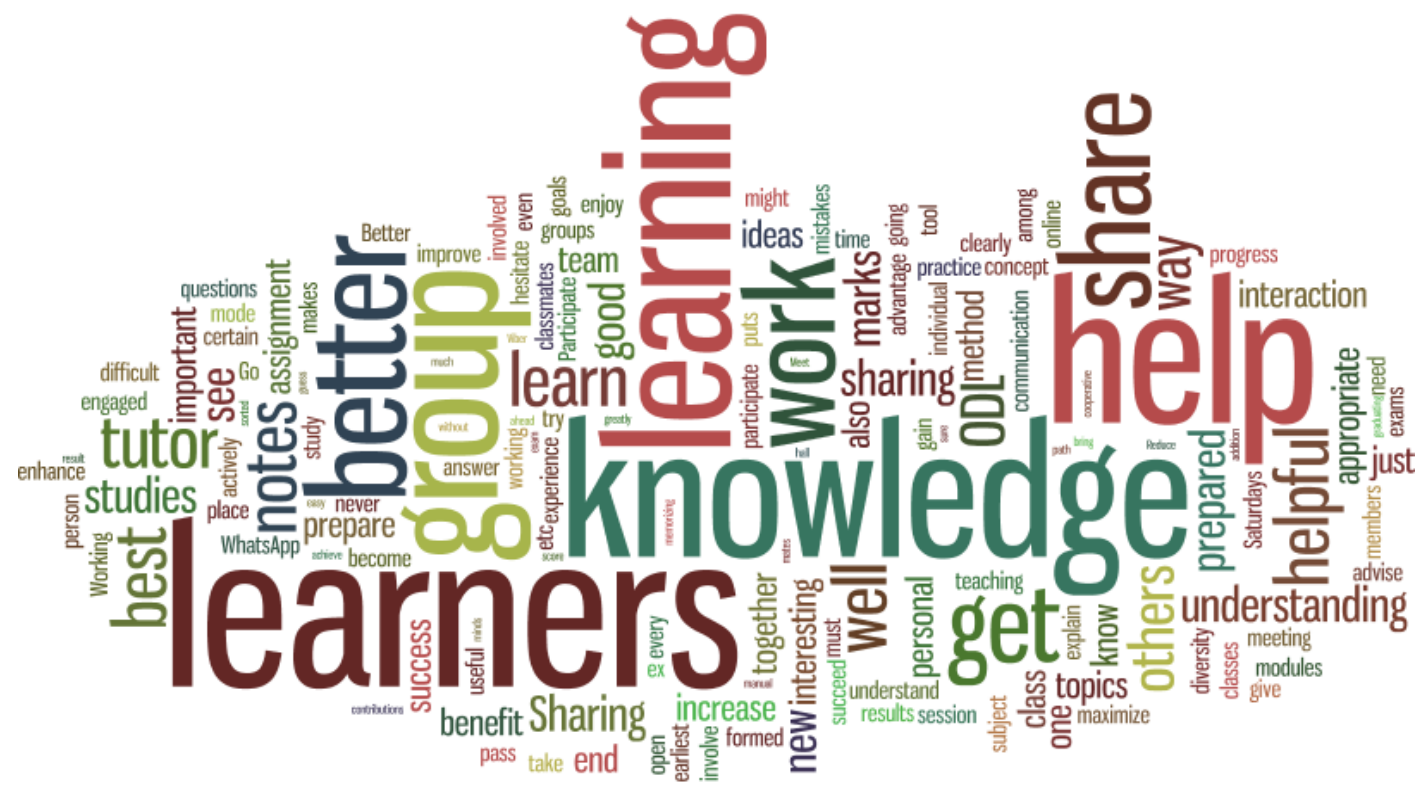

Figure 14. Advice to others to delve in CL activities.

\section{CONCLUSIONS AND RECOMMENDATIONS}

The take-away lessons from this study are numerous. Not all ODL learners participate in CL. In this study one third of the respondents were not availing themselves of the benefits of CL and were thus depriving themselves of an important tool that could have helped them boost their learning performance. Half of them made scarce use of Moodle, hence did not have regular access to online course content, assignments submission instructions and the posted class videos. However, those who participated in CL mentioned a number of learning benefits, thus confirming findings from previous studies (Cole, 2005; Rabbany et al., 2013; Dornyei, 2001; Lentell, 2003; Pedro \& Scott, 2004; Zhang, 2010). The three main ones highlighted in this study include understanding the learning content, discussing the assignments and obtaining better marks (Delucchi, 2006; Muuro et al., 2014). Three quarters of the respondents also mentioned that CL helped them to adapt to the ODL mode. However, they also highlighted a number of obstacles to participating in CL and the major ones include lack of (i) time due to family and professional commitments, (ii) encouragement from tutors and peers and (iii) facilities and logistics to conduct CL meetings. As many learners were not taking advantage of the functionalities of the Moodle platform, they should constantly be reminded, during induction sessions and tutorials of the importance and benefits of mastering this tool for enhancing learning. Tutors too should be sensitized about the benefits of CL and must be trained to impart appropriate skills to learners so that they can participate in CL activities. Their personal involvement in the CL sessions proved to be vital. Tutors' personal involvement in the CL sessions proved to be vital. ODL institutions should allocate adequate meeting places for learners to conduct their CL meetings. They should also provide online platforms as this study confirmed that respondents resorted to this mode for collaborating and exchanging information. This helped them to address the difficulties of finding meeting places and travelling.

Those embarking on the ODL or online learning mode can easily become isolated and miss the benefits of "learning together". CL can be a great contributor to help such learners overcome this isolation and boost their learning experience. However, this study shows that the conduct of CL lacks a structural framework and learners rely on their own initiatives. It is imperative therefore for open and learning institutions to provide learners with an efficient learning framework that enhances learning performance and promotes critical thinking through structured socialization. 


\section{BIODATA and CONTACT ADDRESSES of AUTHORS}

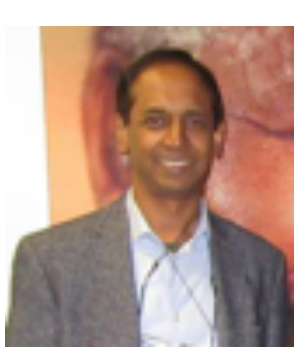

Dr. Perienen APPAVOO, is Head of Research at the Open University of Mauritius. Dr Appavoo has a Ph.D in Educational Technologies. His academic interest areas include the integration of technology in education, open and distance learning, online education and educational leadership. He has over the last six years published more than ten journal articles in peer- reviewed international journals and one book chapter. He has also coauthored two books in Information Technology. Dr Appavoo has more than twenty years of experience in the design and production of educational video programmes.

Perienen APPAVOO

Research Consultancy and Innovation Unit

Adress: Open University of Mauritius, Reduit Mauritius

Phone: +2304038200

E-mail: p.appavoo@open.ac.mu

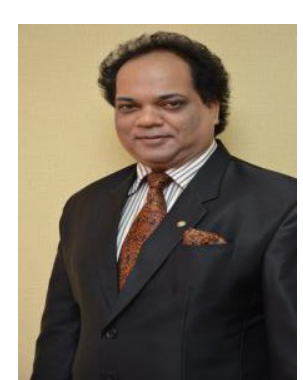

Dr. Kaviraj Sharma SUKON, is the founder Director-General of Open University of Mauritius - the first local ISO Certified public university in Mauritius. After nearly seven years of operation, the Open University of Mauritius has over 5,000 learners. Dr Sukon is also the Chairman of the Mauritius Museums Council. He has been the Chairman of the Board of the Mauritius College of the Air and has previously worked at University of Mauritius, Mauritius Examination Syndicate and Human Resource Development Council. Dr Sukon has led (a) the development of the first National Human Resource Development Plan for Mauritius; (b) the marking of the first International CIE Mathematics paper in Mauritius; and (c) the establishment of the Open University of Mauritius. He has been a consultant for several organisations including UNESCO, ILO, UNDP AND ADEA. He has published research papers and supervised several master's and doctoral theses. He has been a member of the Senate of University of Mauritius and Academic Council of University of Technology, Mauritius. He also holds a honorary position at Imperial College London, UK.

Kaviraj Sharma SUKON

Adress: Open University, Reduit, Mauritius

Phone: +230 4038200

E-mail: directorgeneral@open.ac.mu

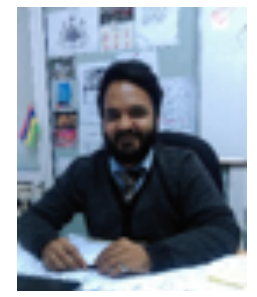

Abheenaye Chauhan GOKHOOL, is a lecturer in Marketing and Management at the Open University of Mauritius. He is also a certified Digital Marketing Professional. His academic interest areas are in Marketing and Management; Digital Marketing, Marketing Communications, International Marketing, Consumer Buyer Behavior, Advertising, Gender Stereotyping, Leadership and Open and Distance learning. Besides being a lecturer, he is also the Programme Manager for several courses.

Abheenaye Chauhan GOKHOOL

Academic Affairs Division

Adress: Open University, Reduit, Mauritius

Phone: +2304038200

E-mail: a.gokhool@open.ac.mu 


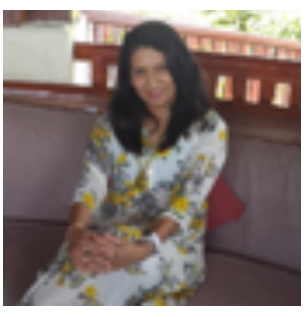

Vandanah GOORIA, is a Programme Manager and Lecturer in Management and Marketing at the Open University of Mauritius. Vandanah holds a master's degree in Business Administration and is currently doing her Doctor of Philosophy in Special Education Needs Management. She has 13 years of experience in public administration of the education sector and has over 5 years of professional and academic experience encompassing development of course materials/programmes, authoring courses, university teaching, market research and surveys. She published research papers in well-known journals and other International Conference proceedings (10th and 11th Annual University Teaching and Learning Higher Education Conferences, ICCS and e-MIG, UNISA 8th TEIR). She co-authored one international book chapter in September 2018 'Technology for Efficient Learner Support Services in Distance Education - Experiences from Developing Countries', published in Springer. Her academic interest areas are mainly Marketing Relationship, Tourism, Customer behaviour, Online marketing, Marketing planning, Open Educational Resources (OER), Special education needs Management, Technology and Open Distance Learning.

Vandanah GOORIA

Academic Department,

Adress: Open University of Mauritius, Reduit, Mauritius

Phone: +2304038200 ,

E-mail: v.gooria@open.ac.mu

\section{REFERENCES}

Amry, B. A. (2014). The impact of WhatsApp mobile social learning on the achievement and attitudes of female learners compared with face to face learning in the classroom. European Scientific Journal, 10(22), 116-136.

Brame, C. (2016). Active learning. Vanderbilt University Center for Teaching. Retrieved 08.08.18 from https://cft.vanderbilt.edu/active-learning/.

Brindley, J.E., Walti, C. \& Blaschke, L.M. (2009). Creating effective collaborative learning groups in an online environment. The International Review of Research in Open and Distributed Leaning, $10(3)$.

Chan, L. (2005). WebCT revolutionized e-learning. UBC Reports, 51(7).

Colbeck, C.L., Campbell, S.E., \& Bjorklund, S.A. (2000). Grouping in the Dark: What college students learn from group projects? The Journal of Higher Education. 71(1), 60-83

Cole, J. (2005). Using Moodle: Teaching with the Popular Open Source Course Management System. Sebastopol: O' Reilly Community Press.

Curtis, D. D., \& Lawson, M. J. (2001). Exploring Collaborative Online Learning. Journal of Asynchronous Learning Networks, 5(1), 21-34.

De Jong, N., Krumeich, J. S. M., \& Verstegen, D. M. L. (2016). To what extent can PBL principles be applied in blended learning: Lessons learned from health master programmes. Medical Teacher, 39(2), 203-211. doi: 10.1080/0142159X.2016.1248915

Delucchi, M. (2006). The efficacy of collaborative learning groups in an undergraduate statistics course. College Teach, 54(2), 244-248.

Dewiyanti, S., Brand-Gruwel, S., Jochems, W., \& Broers, N.J. (2007). Learners' experiences with collaborative learning in asynchronous computer-supported collaborative learning environments. Computers in Human Behaviour, 23, 496-514.

Dirkx, J. M., \& Smith, R.O. (2008). Collaborative Learning: Two perspectives on theory and practice. Retrieved from http://www.irrodl.org/index.php/irrodl/article/view/497/1043

Dornyei, Z. (2001). Teaching and researching motivation. In N. Christopher, \& R. David (Eds.), Applied linguistics in action series. Harlow: Pearson Education Limited. 
Eggen, P., \& Kauchak, D. (2001). Educational psychology: Windows on classrooms (5th ed.). New Jersey, $\mathrm{OH}$ : Pearson Merrill Prentice Hall.

Eichler, G. (2003). E-Learning and communities, supporting the circulation of knowledge pieces. Innovative Internet Community Systems, Lecture Notes in Computer Science, 2877, 48-64.

Ellis, R. (2003). Task-based language learning and teaching. Oxford: Oxford University Press.

Frankola, K. (2001). Why online learners dropout. Workforce, 10, 53-63.

Garrison, D. R., \& Cleveland-Innes, M. (2005). Facilitating cognitive presence in online learning: Interaction is not enough. The American Journal of Distance Education, 19(3), 133-148.

Hrastinski, S., \& Aghaee, N. M. (2012). How are campus learners using social media to support their studies? An explorative interview study. Education and Information Technologies, 17, 451-464.

Jacobs, G.M., Power, M.A., \& Loh, W. I. (2002). The teacher's sourcebook for cooperative learning: practical techniques, basic principles and frequently asked questions. Thousand Oaks: Corwin Press.

Jiang, Y.M. (2009). Applying group work to improve college learners' oral English. Int Edu Stud, 2(3), 136139.

Johnson, D.W., \& Johnson, R.T. (1989). Cooperation and Competition: Theory and research. Edina, MN: Interaction Book Company.

Johnston, C.G., James, R.H., Lye, J.N., \& McDonald, I. M. (2000). An Evaluation of Collaborative Problem Solving for Learning Economics. Journal of Economic Education, 31(1), 13-29.

Joo, Y.J., Lim, K.Y., \& Kim, E.K. (2011). Online university learners' satisfaction and persistence: Examining perceived level of presence, usefulness and ease of use as predictors in a structural model. Computers \& Education, 57(2), 1654-1664.

Jung, I, Choi, S., Lim, C., \& Leem, J. (2002). Effects of different types of interaction on learning achievement, satisfaction, and participation in web-based instruction. Innovations in Education and Teaching International, 39(2), 153-162.

Katz, S., \& O'Donnell, G. (1999). The Cognitive Skill of Coaching Collaboration. In C. Hoadley, \& J. Roschelle (Eds.), Prooceedings of Computer Support for Collaborative Learning (291-299). Stanford University CA: Palo Alto.

Kuo, Y.C., Belland, B.R., \& Kuo, Y.T. (2017). Learning through blogging: Learner's Perspectives in Collaborative Blog-Enhanced Learning Communities. Educational Technology \& Society, 20(2), $37-50$.

Laal, M. and Ghodsi, S.M. (2012) Benefits of Collaborative Learning. Procedia - Social and Behavioral Sciences, 31(1), 486-490.

Laal, M. and Laal, M. (2012). Collaborative learning: what is it?. Procedia -Social and Behavioral Sciences, 31(1), 491-495.

Lan, Y., Sung, Y., \& Chang, K. (2007). A mobile-device-supported peer-assisted learning system for collaborative early ELF reading. Language Learning \& Technology, 11(3), 130-151.

Law, N., \& Wong, E. (2003). Developmental trajectory in knowledge building: An investigation. In B. Wasson, S. Ludvigsen, \& U. Hoppe (Eds.), Designing for change in networked learning environments (pp. 57-66). Dordrecht, Netherlands: Kluwer.

Lee, Y., \& Choi, J. (2013). A structural equation model of predictors of online learning retention. The Internet and Higher Education, 16, 36-42.

Lentell, H. (2003). The Importance of the Tutor in Open and Distance Learning. In A. Tait, \& R. Mills (Eds.), Rethinking Learner Support In Distance Education (pp. 64-76). London: Routledge Falmer.

Lin, L. (2015). Exploring Collaborative Learning: Theoretical and Conceptual Perspectives. Investigating Chinese HE EFL Classrooms. Springer-Verlag Berlin Heidelberg, 11-28. 
Maesin, A., Mansor, M. Shafie, L.A., \& Nayan, S. (2009). A study of collaborative learning among Malaysian undergraduates. Asian Social Journal, 5(7), 70-76.

Mattar, J.A. (2010). Constructivism and Connectivism in Education technology: Active, situated, authentic, experiential, and anchored learning. Technology, 21(2), 1-16.

Mayes, T. (2001). Learning technology and learning relationships. In J. Stephenson (Ed.), Teaching \& learning online pedagogies for new technologies (pp. 16-25). London: Kogan Page.

Muuro, M.E, Wagacga, W.P., Oboko, R., \& Kihoro, J. (2014). Learners' perceived challenges in an online collaborative learning environment: A case of higher learning institutions in Nairobi, Kenya. International Review of Research in Open and Distance Learning, 15(6), 132-161.

Nurmela, K., Palpnen, T., Lehtinen E., \& Hakkarainen, K. (2003). Developing tools for anlayzing CSCL process. In B. Wasson, S. Ludvigsen, \& U. Hoppr (Eds.), Designing for change in networked learning environements (pp. 333-342). Dordrecht, Netherlands: Kluwer.

Nyerere, J.A., Gravenir, F.Q., \& Mse, G.S. (2012). Delivery of open, distance, and e-learning in Kenya. The International Review of Research in Open and Distance Learning, 13(3), 185-205.

Pearson, B.B.C. (2010). Collaborative Learning: Encouraging shy learners to participate in group activities. Always Learning, Educational Publishers LLP Trading. Retrieved from http://www.bbcactive. com/BBCActiveIdeasandResources/EncouragingShyLearnerstoParticipateinGroups.aspx

Pedro, A.W., \& Scott, J. (2004). Factors that influence learners' decision to drop out of online course. JALN, $8(4)$

Picou, A. (2011). Does gender, GPA or age influence test performance in the introductory finance class? A study using linked questions. Review of Business Research, 11(4), 118-126.

Preston, G., Phillips, R., Gosper, M., McNeill, M., Woo, K., \& Green, D. (2010). Web-based lecture technologies: Highlighting the changing nature of teaching and learning. Australian Journal of Educational Technology, 26(6), 717-728.

Rabbany, R., Elatia, S. Takaffoli, M., \& Zaiane, O. R. (2013). Collaborative Learning of Learners in Online Discussion Forums: A Social Network Analysis Perspective. In A. Peña-Ayala (Ed.), Educational Data Mining: Applications and Trends (pp. 441-466).

Retnowati, E. Ayres, P., \& Sweller, J. (2017). Can Collaborative Learning improve the effectiveness of worked examples in Learning Mathematics? Journal of Educational Psychology, 109(5), 666-679

Rovio-Johansson, A. and Lumsden, M. (2012). Collaborative production of pedagogical knowledge: enhancing learners' learning. Journal of Applied Research in Higher Education, 4(1), pp. 72-83.

Sanders, M. (2008). A failure to collaborate. The Chronicle of Higher Education, First Person.

Sansivero, G. (2016). Challenges and advantages of Collaborative learning: Developing workforce readiness in students. Seen Magazines US articles

Schreiber, L.M., \& Valle, B.E. (2013). Social Constructivist teaching strategies in the small group classroom. Small Group Research, 44, 395-411.

Stansfield, M., McLellan, E., \& Connolly, T. (2004). Enhancing learner performance in online learning and traditional face-to-face class delivery. Journal of Information Technology Education, 3, 73-188.

Sun, J. (2016). Multi-dimensional alignment between online instruction and course technology: A learnercentered perpective. Computers \& Education, 101, 102-114

Svolik, M.W. (2009). Power sharing and Leadership Dynamics in authoritarian regimes. American Journal of Political Science. Midwest Political Science Association. 53(2), 447-494

Van Merrienboer, J.J.G., \& Paas, F. (2003). Powerful learning and the many faces of instructional design: Towards a framework for the design of powerful learning environments. In E. De Corte, L. Verschaffel, N. Enstwistle, \& J.J.G. Van Merrienboer (Eds.), Powerful learning environments: Unravelling basic components and dimensions. Oxford: Elsevier Science. 
Vygotsky, L.S. (1978). Mind in society: the development of higher psychological processes. Cambridge: Harvard University Press.

Weidlich, J., \& Bastiaens, T.J., (2018). Technology Matters - The impact of transactional distance on satisfaction in Online Distance Learning, International Review of Research in Open and Distributed Learning, 19(3).

Yazici, H.J. (2005). A study of collaborative learning style and team learning performance. Education and Training Journal, 47(3), 216-229.

Zhang, Y. (2010). Cooperative language learning and foreign language learning and teaching. Journal of Language Teaching and Research, 1(1), 81-83.

Zhu, C. (2012). Learner Satisfaction, Performance and Knowledge Construction in Online Collaborative Learning. Educational Technology \& Society, 15(1), 127-136.

Zygouris-Coe, V. (2012). Collaborative Learning in an online teacher education course: lessons learned. In ICICTE Proceedings (pp. 332-342). 